\title{
High-flow nasal cannula for respiratory failure in adult patients
}

\section{SeungYong Park}

Division of Respiratory, Allergy and Critical Care Medicine, Department of Internal Medicine, Jeonbuk National University Medical School, Jeonju, Korea

The high-flow nasal cannula (HFNC) has been recently used in several clinical settings for oxygenation in adults. In particular, the advantages of HFNC compared with low-flow oxygen systems or non-invasive ventilation include enhanced comfort, increased humidification of secretions to facilitate expectoration, washout of nasopharyngeal dead space to improve the efficiency of ventilation, provision of a small positive end-inspiratory pressure effect, and fixed and rapid delivery of an accurate fraction of inspired oxygen (FiO2) by minimizing the entrainment of room air. HFNC has been successfully used in critically ill patients with several conditions, such as hypoxemic respiratory failure, hypercapneic respiratory failure (exacerbation of chronic obstructive lung disease), post-extubation respiratory failure, pre-intubation oxygenation, and others. However, the indications are not absolute, and much of the proven benefit remains subjective and physiologic. This review discusses the practical application and clinical uses of HFNC in adults, including its unique respiratory physiologic effects, device settings, and clinical indications.

Key Words: high-flow nasal cannula; oxygen; respiratory failure

\section{Review Article}

Received: October 29, 2021

Revised: November 25, 2021

Accepted: November 25, 2021

\section{Corresponding author}

SeungYong Park

Division of Respiratory, Allergy, and

Critical Care Medicine, Department of Internal Medicine, Jeonbuk National University Medical School, 567 Baekje-daero, Deokjin-gu, Jeonju 54896, Korea

Tel: +81-63-250-2571

Fax: +82-63-250-1633

E-mail: cough@jbnu.ac.kr

\section{INTRODUCTION}

Oxygen therapy is typically delivered via low-flow systems (e.g., nasal cannulae or masks) or high-flow systems (e.g., venturi masks or nonrebreathers). The high-flow nasal cannula (HFNC) is a unique mode of noninvasive respiratory support that delivers warmed, humidified oxygen with a fraction of inspired oxygen $\left(\mathrm{FiO}_{2}\right)$ of 0.21 to 1.0 and a flow rate as high as $60 \mathrm{~L} / \mathrm{min}$. HFNC is indicated for patients with respiratory failure due to various underlying conditions.

The benefits of HFNC over conventional oxygen devices (low-flow systems [nasal cannulae or masks] and high-flow systems [Venturi masks]) and noninvasive ventilation (NIV; continuous or bilevel positive airway pressure ventilation) are improved patient comfort and physiologic advantages. The latter include improved oxygenation and ventilation, better pulmonary compliance, reduced anatomical dead space, modest positive end-expiratory pressure, more efficient respiratory effort, reduced work of breathing, and improved secretion clearance [1]. The goal of this review is to examine research on HFNC in adult patients, with an emphasis on its physiological effects, titration of the device, and varied clinical applications.
Copyright (C) 2021 The Korean Society of Critical Care Medicine under the terms of Creative Attributions Non-Commercial License (https:// creativecommons.org/li-censes/by-nc/4.0/) which permits unrestricted noncommercial use, distribution, and reproduction in any medium, provided the original work is properly cited.
This is an Open Access article distributed 


\section{PHYSIOLOGIC EFFECTS}

Supplemental oxygen therapy is the first-line therapy for respiratory failure. Generally, oxygen is provided via low-flow systems (nasal cannulae or masks). However, several disadvantages have been reported relative to high-flow systems, including low efficacy and low tolerance of oxygen delivery. Bubble humidifiers are commonly used with low-flow systems for spontaneously breathing patients, but because the absolute humidity is low, patients still report discomfort, especially dry nose, dry throat, and nasal pain [2,3]. Insufficient heating and humidification also result in poor compliance with these devices. Finally, with conventional treatments in patients with respiratory failure, a disparity exists between the delivered oxygen flow and the inspiratory flow of the patient. The oxygen flow is delivered at a maximum of $15 \mathrm{~L} / \mathrm{min}$, while the inspiratory flow in these patients ranges from $30 \mathrm{~L} / \mathrm{min}$ to greater than $100 \mathrm{~L} / \mathrm{min}$. As a consequence of this large disparity, the fraction of inspired oxygen $\left(\mathrm{FiO}_{2}\right)$ is variable and frequently lower than intended.

Gas from an air/oxygen blender is heated, actively humidified, and then delivered via a heated circuit. The blender can generate a flow as high as $60 \mathrm{~L} / \mathrm{min}$. The physiological effects of gas administered in this manner are outlined in Table 1.

\section{Anatomical Dead Space Washout}

HFNC can flush out the expired carbon dioxide accumulated in the anatomical dead space of the nasopharynx. This decreased accumulation can improve the efficiency of ventilation and thoracoabdominal synchrony and enhance oxygen delivery [4-6]. Thus, improved washout with HFNC relative to other oxygen delivery systems permits a larger fraction of minute ventilation to participate in alveolar gas exchange.

Table 1. Advantages and disadvantages of high-flow nasal cannula treatment

\begin{tabular}{|c|c|}
\hline Advantage & Disadvantage \\
\hline $\begin{array}{l}\text { Comfort due to similarity of } \\
\text { humidified, warmed air to } \\
\text { physiologic conditions of the } \\
\text { airway }\end{array}$ & $\begin{array}{l}\text { Potential discomfort due to high } \\
\text { flow and relatively hot air } \\
\text { sensation }\end{array}$ \\
\hline $\begin{array}{l}\text { Carbon dioxide washout (reduced } \\
\text { anatomical dead space) }\end{array}$ & Not immediately available \\
\hline $\begin{array}{l}\text { Clinician can set precise fraction of } \\
\text { inspired oxygen. }\end{array}$ & $\begin{array}{l}\text { Aerosol-generating procedure that } \\
\text { can potentially increase the risk of } \\
\text { viral transmission }\end{array}$ \\
\hline \multicolumn{2}{|c|}{$\begin{array}{l}\text { Provides low positive end expiratory } \\
\text { pressure effect }\end{array}$} \\
\hline $\begin{array}{l}\text { Leaves mouth free for talking, } \\
\text { eating, or coughing }\end{array}$ & \\
\hline
\end{tabular}

\section{Positive End Expiratory Pressure Effect}

HFNC is an open system; however, the high rate of flow from the cannula resists expiratory airflow and elevates the airway pressure [7]. In adults, as in neonates and infants, HFNC has been shown to exhibit the "positive end expiratory pressure (PEEP) effect," in which it raises the peak nasopharyngeal airway pressure present at the end of expiration [8-10], particularly when the mouth is closed. This "PEEP effect" can reduce the work of breathing, mitigate auto-PEEP (if present), and improve oxygenation. Each added increment of $10 \mathrm{~L} / \mathrm{min}$ of oxygen flow adds approximately $0.7 \mathrm{~cm} \mathrm{H}_{2} \mathrm{O}$ (up to approximately $3 \mathrm{~cm} \mathrm{H}_{2} \mathrm{O}$ ) of PEEP when the patient's mouth is closed and 0.35 $\mathrm{cm} \mathrm{H}_{2} \mathrm{O}$ when it is open [11].

\section{Fraction of Inspired Oxygen}

Physiologically, inspiratory flow and tidal volume vary breathby-breath [12]. Patients with respiratory failure demand higher inspiratory flow rates that exceed the flow rates of standard oxygen supply devices, resulting in the entrainment of room air and a reduction in the $\mathrm{FiO}_{2}$ of the delivered gas. The $\mathrm{FiO}_{2}$ level varies during low-flow oxygen delivery and is generally much lower than predicted by equipment algorithms [13,14]. However, with HFNC, the gas flow rate to the patient is much higher than with low-flow oxygen systems. High flow rates minimize the entrainment of room air, yielding more accurate delivery of oxygen, especially relative to conventional delivery systems. Additionally, elevated flow rates have been demonstrated to lower the respiratory rate while increasing tidal volume, improving the overall pattern of breathing $[9,15]$.

\section{Humidification}

HFNC ventilation systems typically include a heated humidifier. This allows these devices to deliver optimally heated and humidified gas to patients better than conventional oxygen systems. The added humidification increases the mucosal water content, aiding in the removal of secretions and potentially reducing the work of breathing. This also moistens the airway, avoiding the epithelial injury associated with airway desiccation $[16,17]$.

\section{Small Pliable Nasal Prongs (Comfortable Interface)}

HFNC exhibits outstanding acceptance and tolerability resulting from its uniquely soft and pliable nasal prongs (Figure 1). As such, several studies have described greater patient comfort with HFNC than with conventional low-flow or highflow oxygen administered through a face mask or nasal can- 


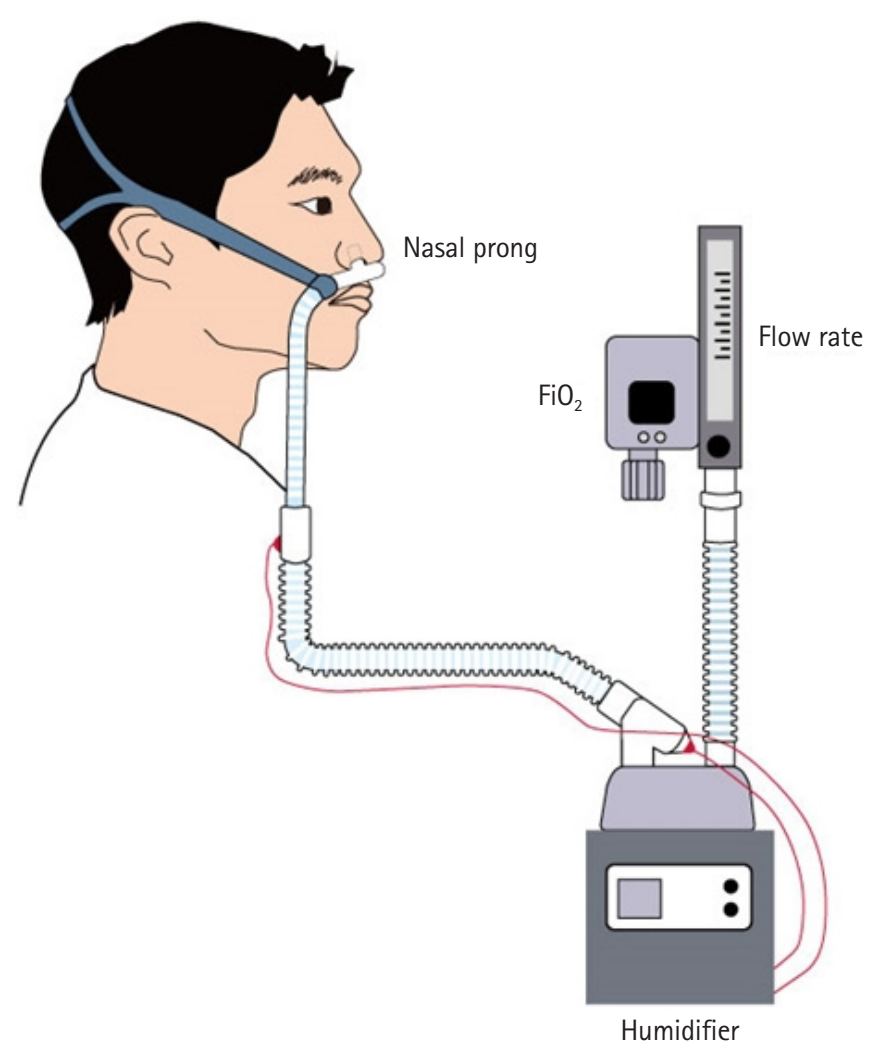

Figure 1. High-flow nasal cannula oxygen device. An air/oxygen blender, allowing a fraction of inspired oxygen $\left(\mathrm{FiO}_{2}\right)$ from 0.21 to 1.0, generates flow up to $60 \mathrm{~L} / \mathrm{min}$. The gas is heated and humidified by an active heated humidifier used during mechanical ventilation. The patient breaths medical gas through a unique large-diameter pliable nasal cannula with a single-limb heated inspiratory circuit.

nula [18-20]. NIV, in turn, is difficult to manage for extended durations, making HFNC an exciting potential alternative for do-not-intubate patients.

\section{CLINICAL SETTINGS (DEVICE TITRATION)}

HFNC is increasingly used to deliver oxygen to critically ill patients, especially those experiencing respiratory failure. However, no recommendations have been established for its practical application. Although HFNC can be administered on an unmonitored floor, it is usually applied in a monitored setting such as the intensive care unit (ICU), intermediate care wards, or emergency department $[6,17]$.

Oxygen gas is adequately heated and humidified and is then delivered through a unique wide-bore nasal cannula, generally made of softer, more pliable plastic than the cannulae for low-flow systems. The cannula fits snugly into the snares and is held in place with a head strap (Figure 1).

Two parameters must be set: the flow rate and the $\mathrm{FiO}_{2}$. The flow rate should be set first, typically at $20 \mathrm{~L} / \mathrm{min}$ to $35 \mathrm{~L} / \mathrm{min}$ (range, $5-60 \mathrm{~L} / \mathrm{min}$ ). Second, the $\mathrm{FiO}_{2}$ (range, $21 \%-100 \%$ ) is set to target a desired peripheral oxygen saturation. The flow rate can subsequently be increased in 5 to $10 \mathrm{~L} / \mathrm{min}$ increments if the respiratory rate fails to improve, oxygenation fails to adequately improve, or breathing remains labored. Both increasing the flow rate and increasing the $\mathrm{FiO}_{2}$ will result in improved peripheral oxygen saturation. We recommend maximizing the flow rate first and attempting to keep the $\mathrm{FiO}_{2} \leq 60 \%$; however, an increase in $\mathrm{FiO}_{2}$ may be necessary to achieve adequate oxygenation.

HFNC is generally well tolerated and can be administered for several days. Patients can be switched to a low-flow system (nasal cannula or mask) once the flow rate reaches $20 \mathrm{~L} / \mathrm{min}$ ute or lower and $\mathrm{FiO}_{2}$ reaches $50 \%$ or lower.

\section{CLINICAL APPLICATIONS}

\section{Acute Hypoxemic Respiratory Failure HFNC versus low-flow oxygen}

The indication of HFNC is supported by randomized trials and observational studies of patients with hypoxemic respiratory failure. While data are conflicting, these studies consistently demonstrate improved oxygenation and a decreased need for intubation when HFNC is used relative to low-flow oxygen systems $[4,5,18,21-34]$. However, studies have failed to show consistent and convincing benefits for mortality, length of ICU and hospital stay, dyspnea, and comfort.

The High Flow Nasal Oxygen Therapy in Resuscitation of Patients with Acute Lung Injury (FLORALI) trial was a large multicenter randomized study in which HFNC was compared with conventional oxygen therapy and NIV [22]. Adults with no prior history of lung disease and respiratory failure were randomly assigned to receive HFNC therapy, oxygen via a nonrebreather face mask, or NIV. Ultimately, the intubation rate (the primary endpoint) was similar among treatment modalities. However, other outcomes included 90-day mortality and ventilator-free days, both of which were notably lower among the patients treated with HFNC than in those treated with NIV or conventional oxygen therapy. In a post hoc examination, HFNC was also associated with lower intubation rates among patients with a partial pressure of oxygen $\left(\mathrm{PaO}_{2}\right) / \mathrm{FiO}_{2}$ ratio lower than 200. However, because overall intubation rates were lower than anticipated, the power of the study was insuf- 
ficient to address this question. Finally, in examining whether delays in intubation that could influence treatment outcomes had been present, the authors concluded that the time to intubation did not differ significantly between HFNC and NIV.

Another important randomized trial involving HFNC was the Randomized Controlled Trial of Humidified High-Flow Nasal Oxygen for Acute Respiratory Distress in the Emergency Department; HOT-ER study, which described the early initiation of HFNC in 322 emergency room patients with hypoxemia. Compared with conventional oxygen therapy, the investigators found that HFNC was not superior [21]. HFNC was associated with lower intubation rates after 24 hours (HFNC, $5.5 \%$; conventional oxygen treatment, $11.6 \%$ ), although this disparity was not statistically significant $(\mathrm{P}=0.053)$. The groups exhibited similar 90-day mortality rates (HFNC, 21.2\%; conventional oxygen treatment, $17.4 \%$ ).

The conflicting results between the FLORALI and HOT-ER trials may relate to key differences in study design and patient characteristics, such as underlying comorbidities. In the FLORALI trial, the most common cause of respiratory failure was pneumonia (approximately $80 \%$ of patients). In contrast, in the HOT-ER study, only approximately one-fourth of patients had pneumonia. Additionally, over half of the HOT-ER study participants were diagnosed with asthma, heart failure, or chronic obstructive lung disease (COPD), diagnoses that were exclusion criteria for the FLORALI trial. In the FLORALI study, participants received 48 hours of continuous HFNC, while HOTER lacked any specific HFNC treatment protocol, potentially resulting in insufficient HFNC treatment in the latter study. HOT-ER also did not compare HFNC with NIV. In addition, the studies differed in the details of the high flow settings used; for instance, the flow rate was set $10 \mathrm{~L} / \mathrm{min}$ lower in the HOTER than in the FLORALI protocol. Although a small disparity, the greater flow rate in the FLORALI study may have improved $\mathrm{CO}_{2}$ clearance among the participants, reducing the work of breathing and leading to fewer intubations.

In a meta-analysis of 14 trials, the authors compared HFNC with conventional oxygen therapy in patients with acute hypoxemic respiratory failure. HFNC treatment had little or no impact on the intubation rate (26\% in both groups; odds ratio, 0.98; 95\% confidence interval [CI], 0.34-2.82) or the mortality rate $26 \%$ for HFNC vs. $27 \%$ for conventional oxygen therapy; relative risk [RR], 0.97; 95\% CI, 0.82-1.14) [35]. The same meta-analysis also reported reduced dyspnea and improved comfort among the HFNC group as well as a possible reduction in hospital-acquired pneumonia, but the effects on ICU admissions and length of stay were uncertain.

In another meta-analysis of nine trials that compared HFNC to low-flow oxygen in patients with hypoxemic respiratory failure, HFNC was associated with a decreased need for both intubation (RR, 0.85; 95\% CI, 0.74-0.99) and escalation of respiratory support (RR, 0.71; 95\% CI, 0.51-0.98) [36]. However, no differences were observed in the mortality rate, length of stay, or patient dyspnea and comfort.

Moreover, in a network meta-analysis, HFNC was shown to reduce the intubation rate in patients with acute hypoxemic respiratory failure compared with conventional low-flow oxygen, but no impact was observed on mortality (RR, 0.76; 95\% CI, 0.55-0.99) [37].

\section{HFNC versus NIV}

Conflicting evidence exists about whether NIV is beneficial to patients with hypoxemic nonhypercapnic respiratory failure [38-46]. A network meta-analysis of 25 randomized trials examined outcomes in patients with acute hypoxemic respiratory failure who were treated with noninvasive modalities (helmet NIV, facemask NIV, and HFNC) compared with those of patients who were treated with low-flow oxygen [37]. Mortality was lower among patients treated with helmet or face mask NIV than in those treated with low-flow oxygen (helmet NIV: RR, 0.40; 95\% CI, 0.24-0.6; face mask NIV: RR, 0.83; 95\% CI, 0.68-0.99). All three noninvasive modalities were associated with lower intubation rates (helmet NIV: RR, 0.26; 95\% CI, 0.14-0.46; face mask NIV: RR, 0.76; 95\% CI, 0.62-0.90; HFNC: RR, 0.76; 95\% CI, 0.55-0.99). However, this network meta-analysis should be interpreted with caution due to significant heterogeneity and risk of bias due to lack of blinding, as well as a wide range of etiologies for respiratory failure and illness severity among participants. In addition, the mortality benefit was not found among patients with severe hypoxemia $\left(\mathrm{a} \mathrm{PaO}_{2} /\right.$ $\mathrm{FiO}_{2}$ ratio $<200 \mathrm{~mm} \mathrm{Hg}$ ).

In a meta-analysis that included 29 randomized trials with mixed populations of participants who had acute respiratory failure, HFNC was compared with NIV [42]. HFNC was associated with lower rates of mortality (RR, 0.44; 95\% CI, 0.24-0.79), intubation (RR, 0.71; 95\% CI, 0.53-0.95), and possibly hospital-acquired pneumonia (RR, 0.46; 95\% CI, 0.15-1.45) and improved patient comfort. However, interpretation of the analysis is limited by the small sample size and heterogeneity in the study design, patient population characteristics, type of respiratory failure, and outcomes. Despite these limitations, HFNC appears to be at least non-inferior and is an acceptable choice 
in this clinical setting.

With regard to devices, helmet NIV was compared with HFNC in another small study of severely hypoxemic patients [34]. Helmet NIV was associated with greater improvements in oxygenation, a reduction in dyspnea and respiratory effort, and similar levels of $\mathrm{PaCO}_{2}$.

Concerns have been raised regarding whether the use of HFNC can potentially delay necessary intubation and worsen outcomes [47]. As a result, when HFNC is used, clinicians should remain vigilant to signs of respiratory failure that necessitate intubation and mechanical ventilation. Patients who are not tachypneic may experience success with HFNC despite a relatively high $\mathrm{FiO}_{2}$. The ROX index (peripheral arterial oxygen saturation/fraction of inspired oxygen [expressed as a percentage]/respiratory rate) may also help guide clinicians in this regard. In one small series, a ROX index of $>4.88$ at 2, 6 , and 12 hours after initiation of HFNC was shown to indicate a lower likelihood of subsequent endotracheal intubation. Further studies are needed to validate the value of ROX in this population before it can be routinely used.

\section{Acute Hypercapnic Respiratory Failure}

Hypercapnic respiratory failure is another frequent clinical situation that can arise from acute exacerbation of COPD. For patients with this condition, when other oxygen devices have failed, NIV has been the primary treatment for respiratory support before endotracheal intubation. However, because of poor mask compliance, it is inappropriate for some patients $[48,49]$. Among these patients with hypercapnic respiratory failure, since HFNC tends to be well-tolerated, it can frequently be utilized to manage the condition successfully [50].

Although HFNC does not provide active inspiratory support in COPD patients, the technique has been shown to increase tidal volume [51]. Nilius et al. [52] found varied effects of HFNC on hypercapnic respiratory failure from COPD; for some individuals, the frequency of breathing was depressed, while for others, $\mathrm{PaCO}_{2}$ was lowered. Among stable patients with COPD, HFNC also increases the capacity for exercise, providing improved oxygenation relative to spontaneous breathing [53]. These results suggest that, for certain forms of hypercapnic respiratory failure, HFNC is an extremely promising therapeutic option.

\section{Pre-intubation Oxygenation}

During intubation support, preoxygenation is routinely used to prevent desaturation. Most experts use conventional systems and bag-mask ventilation to deliver oxygen prior to intubation; the bag mask or oxygen mask is temporarily removed for the intubation procedure. Although not routine, HFNC is an acceptable method to provide oxygen to patients undergoing intubation, both before (preoxygenation) and during the procedure (to prevent desaturation). However, data regarding the value of HFNC for preoxygenation prior to intubation are conflicting [54-57].

Several trials have shown improved oxygenation when HFNC strategies are used. One randomized single-center study compared 4 minutes of preoxygenation with HFNC $\left(100 \% \mathrm{FiO}_{2}\right.$ at $60 \mathrm{~L} /$ minute) together with concomitant NIV (10 $\mathrm{cm} \mathrm{H}_{2} \mathrm{O}$ pressure support ventilation and $5 \mathrm{~cm} \mathrm{H}_{2} \mathrm{O}$ PEEP) with NIV alone prior to intubation. HFNC/NIV was associated with higher peripheral oxygen saturation ( $100 \%$ vs. $96 \%)$ and fewer patients with episodes of desaturation below $80 \%$ ( $0 \%$ vs. $21 \%$ ) [54]. Miguel-Montanes et al. [55] reported similar results in a study of 101 patients, where compared with a nonrebreather mask, peripheral oxygen saturation levels at the end of the preoxygenation period were higher with HFNC (100\% vs. 94\%) and fewer patients exhibited episodes of severe hypoxemia (2\% vs. $14 \%$ ). Overall, HFNC was associated with a significant decrease in the prevalence of severe hypoxemia, and the authors concluded that its application could improve the safety of patients while they are intubated in the ICU.

In contrast, in a multicenter study of 124 patients undergoing intubation who had severe hypoxemia $\left(\mathrm{PaO}_{2} / \mathrm{FiO}_{2}\right.$ ratio $<300 \mathrm{~mm} \mathrm{Hg}$, respiratory rate $>30$ breaths $/ \mathrm{min}$, and a $\mathrm{FiO}_{2}$ $>50 \%$ to achieve a saturation of $>90 \%$ ), HFNC did not reduce the lowest saturation during intubation when compared with preoxygenation using a conventional high-flow oxygen face mask [56]. The discordant results may be explained by differences between the studies in the indications for intubation and severity of hypoxemia prior to intubation.

\section{Post-extubation (Preventing Re-intubation)}

Every patient should be oxygenated following extubation. For most patients, this goal is achieved with low-flow systems (nasal prongs or simple masks). When a higher-flow system is required, Venturi masks or HFNC may be applied. The choice of oxygen devices should be individualized and depends on factors including oxygen requirement, the etiology of respiratory failure, and patient preferences.

The efficacy of HFNC in the post-extubation periods was best illustrated in a trial of 527 patients (mixed postsurgical and medical) at low risk for reintubation following extubation. 
For 24 hours post-extubation, HFNC was associated with less frequent reintubations than occurred when conventional oxygen was used ( $4.9 \%$ vs. $12.2 \%$ ), as well as improved secretion clearance, with 14 patients needed to treat to prevent 1 reintubation [57]. In patients at high risk for reintubation, HFNC and NIV were compared in a randomized trial of 604 patients (mixed surgical and medical populations). After 72 hours, $22.8 \%$ of the HFNC group required reintubation compared to $19.1 \%$ in the NIV group [58]. While the length of the ICU stay was lower in those treated with HFNC, no differences were observed in the rates of mortality, sepsis, or multiorgan failure. Additionally, although $20 \%$ of participants in this trial were patients with moderate to severe COPD, these data are insufficient to make a robust recommendation in favor of HFNC for patients with COPD with chronic hypercapnia, a population in which the evidence and guidelines favor NIV.

A meta-analysis of 9 trials reported that HFNC was associated with reduced reintubation rates ( $R R, 0.46$; 95\% CI, 0.30-0.70) and incidence of post-extubation respiratory failure (RR, 0.52 ; 95\% CI, 0.30-0.91) compared with conventional oxygen therapy [59]. However, compared with NIV, HFNC is not superior to NIV with regard to the rates of reintubation or post-extubation respiratory failure.

\section{Postoperative Respiratory Failure}

Postoperative respiratory failure accounts for more than $20 \%$ of all patients receiving ventilatory support [60,61]. Respiratory failure requiring unplanned reintubation in the postoperative period is associated with high morbidity, leading to a longer hospital stay and an increase in 30-day mortality [62-64]. The risk of reintubation was greatest within the first 6 hours after primary extubation, with consequences such as pneumonia (including aspiration), pulmonary edema, atelectasis, airway obstruction, and impaired brain function.

Generally, moderate evidence favors NIV as a technique for the prevention of reintubation in this situation [65]. Consequently, randomized trials evaluating the efficacy of HFNC are lacking; thus, HFNC is not typically used as a first-line therapy to prevent or manage postoperative respiratory failure. That said, it may be a reasonable alternative, particularly for patients who do not tolerate NIV well.

Hernández et al. [57] reported that the immediate application of HFNC was associated with a lower risk of respiratory failure and reintubation at 72 hours when compared with conventional oxygen therapy. In a study by Corley et al. [66], 155 obese patients (body mass index $30 \mathrm{~kg} / \mathrm{m}^{2}$ ) undergoing cardio- pulmonary bypass surgery were assigned to either the HFNC group (35-50 L/min) or the nasal cannula or face mask group (2-6 L/min) for 8 hours post-extubation. The groups were similar with regard to oxygenation, dyspnea, and the radiographic features of atelectasis. In another study, Yu et al. [67] compared

HFNC with conventional oxygen treatment after thoracoscopic lobectomy. A total of 110 patients at moderate to high risk of reintubation were randomized postoperatively to receive either HFNC (35-60 L/min) or low-flow oxygen administered via nasal cannula or face mask. HFNC treatment was associated with a lower rate of hypoxemia ( $12 \%$ vs. $29 \%$ ) and a decreased need for NIV (4\% vs. $17 \%$ ). Among the participants receiving conventional oxygen therapy, five reintubations were required, compared with none in the HFNC group.

In a study comparing HFNC with NIV, 830 patients who either developed or were at risk of developing acute respiratory failure after cardiothoracic surgery were randomly assigned to receive either HFNC or NIV. The HFNC treatment was conducted at $50 \mathrm{~L} / \mathrm{min}$ and an $\mathrm{FiO}_{2}$ of $50 \%$, whereas NIV involved bilevel positive airway pressure for at least 4 hours each day (pressure support, $8 \mathrm{~cm} \mathrm{H} \mathrm{H}_{2} \mathrm{O}$; PEEP, $4 \mathrm{~cm} \mathrm{H}_{2} \mathrm{O}$ ) [68]. No statistically significant differences were observed between the HFNC and NIV groups in treatment failure rate (reintubation, switch to the other treatment, or treatment discontinuation; HFNC $21 \%$ and NIV 22\%). Similarly, the mortality rates were not statistically different (7\% and $6 \%$, respectively). However, skin breakdown, as expected, was more commonly encountered with NIV (10\% vs. $3 \%)$.

In a meta-analysis of seven randomized trials involving 2,781 patients, HFNC was associated with a similar reintubation rate to both conventional oxygen therapy (RR, 0.58; 95\% CI, 0.21-1.60) and NIV (RR, 1.11; 95\% CI, 0.88-1.40) [69]. However, in a subgroup analysis of critically-ill patients, the HFNC group exhibited a lower reintubation rate than the conventional oxygen therapy group (RR, 0.35; 95\% CI, 0.19-0.64).

In another meta-analysis of 14 studies, HFNC was associated with a statistically insignificant reduction in intubation rate and a reduction in length of hospital stay [70]. In contrast, in a subsequent meta-analysis of 9 trials, compared with conventional oxygen therapy, the use of HFNC postoperatively lowered reintubation rates (RR, 0.32; 95\% CI, 0.12-0.88) and decreased the need to escalate respiratory support (e.g., switching to NIV; RR, 0.54; 95\% CI, 0.31-0.94) [59]. However, HFNC had no effect on mortality rate, length of ICU or hospital stay, or rate of postoperative hypoxia. 
Acute Hypoxemic Respiratory Failure in Immunosuppressed Patients

The mortality rate is relatively high among immunosuppressed patients with acute respiratory failure who need mechanical ventilation [71]. In this situation, NIV is recommended as firstline therapy, and it has been found to be effective in relieving sensations of dyspnea. In two studies, results have indicated that NIV is associated with less frequent intubations and lower mortality relative to conventional oxygen therapy [72].

A post hoc examination of the FLORALI study [27] indicated that among immunosuppressed patients, NIV was associated with more frequent intubation and a higher mortality rate than conventional oxygen therapy or HFNC [23]. A retrospective study of patients with cancer suggested that HFNC treatment was associated with a lower 28-day mortality rate than treatment with conventional oxygen therapy, NIV, or both (35\% in the HFNC group vs. $57 \%$ in the non-HFNC group) [73]. When HFNC was compared with NIV as first-line therapy in a prospective observational study, it was found to be associated with reduced frequency of intubation ( $35 \%$ vs. $55 \%$, respectively) and reduced mortality (20\% vs. $40 \%$, respectively) [74]. Notably, however, HFNC was not effective as a rescue treatment after the failure of conventional oxygen therapy or NIV [24], indicating that HFNC is best suited for early application.

Additionally, HFNC has been observed to reduce the rate of respiration and dyspnea in immunosuppressed patients, resembling its effects in patients who are not immunosuppressed [26,75-77]. Thus, HFNC may be a more easily tolerated alternative device that can provide adequate oxygenation and effective palliation, even for those immunosuppressed, "do not intubate" patients.

\section{Acute Hypoxemic Respiratory Failure in COVID-19}

When the oxygen requirement or work of breathing is increased, treatment options are HFNC, an NIV device, or invasive mechanical ventilation after intubation. Generally, clinical physicians favor noninvasive modalities (HFNC or NIV) over invasive mechanical ventilation.

While one retrospective study reported reduced rates of intubation and mechanical ventilation with HFNC [78], another retrospective study including noninvasive modalities reported no differences in the intubation rate for patients for coronavirus disease 2019 (COVID-19) treated with HFNC (29\%), continuous positive airway pressure $(25 \%)$, or other modes of NIV (28\%) [79]. Additionally, no differences in mortality were observed.
Grieco et al. [80] compared helmet NIV and HFNC in 110 individuals with moderate to severe acute hypoxemic respiratory failure due to COVID-19. No significant difference was observed in days free of respiratory support at the 28-day mark (helmet NIV, 20 days; HFNC, 18 days). However, patients receiving helmet NIV had lower rates of intubation (30\% vs. $51 \%$ ) and experienced more days free of invasive mechanical ventilation ( 28 vs. 25 days).

HFNC is an aerosol-generating procedure that can potentially increase the risk of viral transmission. In spontaneously breathing patients with suspected or documented COVID-19, when HFNC is used, airborne in addition to standard precautions should be undertaken (i.e., full personal protective equipment; placing a surgical mask on the patient during HFNC when health care workers are in the room or the patient is being transported, or starting at the lowest effective flow rate).

\section{CONTRAINDICATIONS}

No randomized clinical trials have reported contraindications of HFNC as a primary endpoint. As such, no absolute contraindications have been identified. Relative contraindications to HFNC include any factor that prevents a nasal cannula from being appropriately fitted, such as irregularities of the nose, face, or airway or a history of surgery of those regions. Some experts avoid HFNC following upper airway surgery to avoid the theoretical risk that the high pressure may precipitate venous thromboembolism.

\section{CONCLUSIONS}

The HFNC is a method of respiratory support in which a high flow of humidified and heated oxygen is delivered at a set concentration via a unique device. HFNC is being increasingly used for patients with respiratory failure of diverse etiologies.

The advantages of HFNC over conventional oxygen systems or NIV include improved comfort, the facilitation of expectoration due to greater humidification of secretions, the washout of upper respiratory dead space to improve ventilation efficiency, a small positive airway pressure effect, and high flow rates to minimize the entrainment of room air for reliable delivery of $\mathrm{FiO}_{2}$.

HFNC has been successfully used in several settings such as severe acute respiratory failure, extubation failure, peri-intubation, postoperative respiratory failure, and others. However, 
the indications are not absolute, with much of the proven benefit subjective and physiologic. The choice of oxygen delivery system should be patient-specific, and factors to consider include institutional availability, clinicians' judgment, patients' preferences, the level of necessity for ventilation and PEEP, and hypoxemic severity.

\section{CONFLICT OF INTEREST}

No potential conflict of interest relevant to this article was reported.

\section{ACKNOWLEDGMENTS}

This paper was supported by the fund of the Biomedical Research Institute at Jeonbuk National University Hospital. Jeonbuk National University Hospital played no role in the design of this study; collection, analysis, and interpretation of data; or writing of the manuscript.

\section{ORCID}

SeungYong Park https://orcid.org/0000-0002-3774-4375

\section{REFERENCES}

1. Qaseem A, Etxeandia-Ikobaltzeta I, Fitterman N, Williams JW Jr, Kansagara D; Clinical Guidelines Committee of the American College of Physicians, et al. Appropriate use of high-flow nasal oxygen in hospitalized patients for initial or postextubation management of acute respiratory failure: a clinical guideline from the American College of Physicians. Ann Intern Med 2021;174:977-84.

2. Campbell EJ, Baker MD, Crites-Silver P. Subjective effects of humidification of oxygen for delivery by nasal cannula: a prospective study. Chest 1988;93:289-93.

3. Chanques G, Constantin JM, Sauter M, Jung B, Sebbane M, Verzilli D, et al. Discomfort associated with underhumidified high-flow oxygen therapy in critically ill patients. Intensive Care Med 2009;35:996-1003.

4. Sztrymf B, Messika J, Mayot T, Lenglet H, Dreyfuss D, Ricard JD. Impact of high-flow nasal cannula oxygen therapy on intensive care unit patients with acute respiratory failure: a prospective observational study. J Crit Care 2012;27:324.

5. Sztrymf B, Messika J, Bertrand F, Hurel D, Leon R, Dreyfuss D, et al. Beneficial effects of humidified high flow nasal oxygen in critical care patients: a prospective pilot study. Intensive Care Med 2011;37:1780-6

6. Lenglet H, Sztrymf B, Leroy C, Brun P, Dreyfuss D, Ricard JD. Humidified high flow nasal oxygen during respiratory failure in the emergency department: feasibility and efficacy. Respir Care 2012;57:1873-8.

7. Parke RL, McGuinness SP. Pressures delivered by nasal high flow oxygen during all phases of the respiratory cycle. Respir Care 2013;58:1621-4.

8. Parke R, McGuinness S, Eccleston M. Nasal high-flow therapy delivers low level positive airway pressure. Br J Anaesth 2009;103:886-90.

9. Corley A, Caruana LR, Barnett AG, Tronstad O, Fraser JF. Oxygen delivery through high-flow nasal cannulae increase end-expiratory lung volume and reduce respiratory rate in post-cardiac surgical patients. Br J Anaesth 2011;107:998-1004.

10. Okuda M, Tanaka N, Naito K, Kumada T, Fukuda K, Kato Y, et al. Evaluation by various methods of the physiological mechanism of a high-flow nasal cannula (HFNC) in healthy volunteers. BMJ Open Respir Res 2017;4:e000200.

11. Parke RL, Eccleston ML, McGuinness SP. The effects of flow on airway pressure during nasal high-flow oxygen therapy. Respir Care 2011;56:1151-5

12. Benchetrit G. Breathing pattern in humans: diversity and individuality. Respir Physiol 2000;122:123-9.

13. Markovitz GH, Colthurst J, Storer TW, Cooper CB. Effective inspired oxygen concentration measured via transtracheal and oral gas analysis. Respir Care 2010;55:453-9.

14. Bazuaye EA, Stone TN, Corris PA, Gibson GJ. Variability of inspired oxygen concentration with nasal cannulas. Thorax 1992;47:609-11.

15. Riera J, Pérez P, Cortés J, Roca O, Masclans JR, Rello J. Effect of high-flow nasal cannula and body position on end-expiratory lung volume: a cohort study using electrical impedance tomography. Respir Care 2013;58:589-96.

16. Williams R, Rankin N, Smith T, Galler D, Seakins P. Relationship between the humidity and temperature of inspired gas and the function of the airway mucosa. Crit Care Med 1996;24:1920-9.

17. Hasani A, Chapman TH, McCool D, Smith RE, Dilworth JP, Agnew JE. Domiciliary humidification improves lung mucociliary clearance in patients with bronchiectasis. Chron Respir Dis 2008;5:81-6.

18. Roca O, Riera J, Torres F, Masclans JR. High-flow oxygen therapy in acute respiratory failure. Respir Care 2010;55:408-13.

19. Tiruvoipati R, Lewis D, Haji K, Botha J. High-flow nasal oxygen vs high-flow face mask: a randomized crossover trial in extu- 
bated patients. J Crit Care 2010;25:463-8.

20. Rittayamai N, Tscheikuna J, Rujiwit P. High-flow nasal cannula versus conventional oxygen therapy after endotracheal extubation: a randomized crossover physiologic study. Respir Care 2014;59:485-90.

21. Jones PG, Kamona S, Doran O, Sawtell F, Wilsher M. Randomized controlled trial of humidified high-flow nasal oxygen for acute respiratory distress in the emergency department: the HOT-ER Study. Respir Care 2016;61:291-9.

22. Frat JP, Thille AW, Mercat A, Girault C, Ragot S, Perbet S, et al. High-flow oxygen through nasal cannula in acute hypoxemic respiratory failure. N Engl J Med 2015;372:2185-96.

23. Frat JP, Ragot S, Girault C, Perbet S, Prat G, Boulain T, et al. Effect of non-invasive oxygenation strategies in immunocompromised patients with severe acute respiratory failure: a post-hoc analysis of a randomised trial. Lancet Respir Med 2016;4:64652.

24. Lemiale V, Resche-Rigon M, Mokart D, Pène F, Argaud L, Mayaux J, et al. High-flow nasal cannula oxygenation in immunocompromised patients with acute hypoxemic respiratory failure: a Groupe de Recherche Respiratoire en Réanimation Onco-Hématologique Study. Crit Care Med 2017;45:e274-80.

25. Rello J, Pérez M, Roca O, Poulakou G, Souto J, Laborda C, et al. High-flow nasal therapy in adults with severe acute respiratory infection: a cohort study in patients with 2009 influenza A/ H1N1v. J Crit Care 2012;27:434-9.

26. Lee HY, Rhee CK, Lee JW. Feasibility of high-flow nasal cannula oxygen therapy for acute respiratory failure in patients with hematologic malignancies: a retrospective single-center study. J Crit Care 2015;30:773-7.

27. Roca O, de Acilu MG, Caralt B, Sacanell J, Masclans JR; ICU Collaborators. Humidified high flow nasal cannula supportive therapy improves outcomes in lung transplant recipients readmitted to the intensive care unit because of acute respiratory failure. Transplantation 2015;99:1092-8.

28. Carratalá Perales JM, Llorens P, Brouzet B, Albert Jiménez AR, Fernández-Cañadas JM, Carbajosa Dalmau J, et al. High-flow therapy via nasal cannula in acute heart failure. Rev Esp Cardiol 2011;64:723-5.

29. Messika J, Ben Ahmed K, Gaudry S, Miguel-Montanes R, Rafat C, Sztrymf B, et al. Use of high-flow nasal cannula oxygen therapy in subjects with ARDS: a 1-year observational study. Respir Care 2015;60:162-9.

30. Baldomero AK, Melzer AC, Greer N, Majeski BN, MacDonald R, Linskens EJ, et al. Effectiveness and harms of high-flow nasal oxygen for acute respiratory failure: an evidence report for a clinical guideline from the American College of Physicians. Ann Intern Med 2021;174:952-66.

31. Calvano TP, Sill JM, Kemp KR, Chung KK. Use of a high-flow oxygen delivery system in a critically ill patient with dementia. Respir Care 2008;53:1739-43.

32. Boyer A, Vargas F, Delacre M, Saint-Léger M, Clouzeau B, Hilbert G, et al. Prognostic impact of high-flow nasal cannula oxygen supply in an ICU patient with pulmonary fibrosis complicated by acute respiratory failure. Intensive Care Med 2011;37:558-9.

33. Lacroix G, Pons F, D’Aranda E, Legodec J, Romanat PE, Goutorbe P. High-flow oxygen, a therapeutic bridge while awaiting thrombolysis in pulmonary embolism? Am J Emerg Med 2013;31:463.

34. Grieco DL, Menga LS, Raggi V, Bongiovanni F, Anzellotti GM, Tanzarella ES, et al. Physiological comparison of high-flow nasal cannula and helmet noninvasive ventilation in acute hypoxemic respiratory failure. Am J Respir Crit Care Med 2020;201:303-12.

35. Mauri T, Turrini C, Eronia N, Grasselli G, Volta CA, Bellani G, et al. Physiologic effects of high-flow nasal cannula in acute hypoxemic respiratory failure. Am J Respir Crit Care Med 2017;195:1207-15.

36. Rochwerg B, Granton D, Wang DX, Helviz Y, Einav S, Frat JP, et al. High flow nasal cannula compared with conventional oxygen therapy for acute hypoxemic respiratory failure: a systematic review and meta-analysis. Intensive Care Med 2019;45:56372.

37. Ferreyro BL, Angriman F, Munshi L, Del Sorbo L, Ferguson ND, Rochwerg B, et al. Association of noninvasive oxygenation strategies with all-cause mortality in adults with acute hypoxemic respiratory failure: a systematic review and meta-analysis. JAMA 2020;324:57-67.

38. Ferrer M, Esquinas A, Leon M, Gonzalez G, Alarcon A, Torres A. Noninvasive ventilation in severe hypoxemic respiratory failure: a randomized clinical trial. Am J Respir Crit Care Med 2003;168:1438-44.

39. Martin TJ, Hovis JD, Costantino JP, Bierman MI, Donahoe MP, Rogers RM, et al. A randomized, prospective evaluation of noninvasive ventilation for acute respiratory failure. Am J Respir Crit Care Med 2000;161(3 Pt 1):807-13.

40. Antonelli M, Conti G, Rocco M, Bufi M, De Blasi RA, Vivino G, et al. A comparison of noninvasive positive-pressure ventilation and conventional mechanical ventilation in patients with acute respiratory failure. N Engl J Med 1998;339:429-35.

41. Delclaux C, L'Her E, Alberti C, Mancebo J, Abroug F, Conti G, 
et al. Treatment of acute hypoxemic nonhypercapnic respiratory insufficiency with continuous positive airway pressure delivered by a face mask: a randomized controlled trial. JAMA 2000;284:2352-60.

42. Keenan SP, Sinuff T, Cook DJ, Hill NS. Does noninvasive positive pressure ventilation improve outcome in acute hypoxemic respiratory failure?: a systematic review. Crit Care Med 2004;32:2516-23.

43. Hernandez G, Fernandez R, Lopez-Reina P, Cuena R, Pedrosa A, Ortiz R, et al. Noninvasive ventilation reduces intubation in chest trauma-related hypoxemia: a randomized clinical trial. Chest 2010;137:74-80.

44. Faria DA, da Silva EM, Atallah ÁN, Vital FM. Noninvasive positive pressure ventilation for acute respiratory failure following upper abdominal surgery. Cochrane Database Syst Rev 2015;2015:CD009134.

45. Xu XP, Zhang XC, Hu SL, Xu JY, Xie JF, Liu SQ, et al. Noninvasive ventilation in acute hypoxemic nonhypercapnic respiratory failure: a systematic review and meta-analysis. Crit Care Med 2017;45:e727-33.

46. Schettino G, Altobelli N, Kacmarek RM. Noninvasive positive-pressure ventilation in acute respiratory failure outside clinical trials: experience at the Massachusetts General Hospital. Crit Care Med 2008;36:441-7.

47. Kang BJ, Koh Y, Lim CM, Huh JW, Baek S, Han M, et al. Failure of high-flow nasal cannula therapy may delay intubation and increase mortality. Intensive Care Med 2015;41:623-32.

48. Ozyilmaz E, Ugurlu AO, Nava S. Timing of noninvasive ventilation failure: causes, risk factors, and potential remedies. BMC Pulm Med 2014;14:19.

49. Nicolini A, Ferrera L, Santo M, Ferrari-Bravo M, Del Forno M, Sclifò F. Noninvasive ventilation for hypercapnic exacerbation of chronic obstructive pulmonary disease: factors related to noninvasive ventilation failure. Pol Arch Med Wewn 2014;124:525-31.

50. Millar J, Lutton S, O'Connor P. The use of high-flow nasal oxygen therapy in the management of hypercarbic respiratory failure. Ther Adv Respir Dis 2014;8:63-4.

51. Bräunlich J, Beyer D, Mai D, Hammerschmidt S, Seyfarth HJ, Wirtz H. Effects of nasal high flow on ventilation in volunteers, COPD and idiopathic pulmonary fibrosis patients. Respiration 2013;85:319-25.

52. Nilius G, Franke KJ, Domanski U, Rühle KH, Kirkness JP, Schneider H. Effects of nasal insufflation on arterial gas exchange and breathing pattern in patients with chronic obstructive pulmonary disease and hypercapnic respiratory failure. Adv Exp Med
Biol 2013;755:27-34

53. Chatila W, Nugent T, Vance G, Gaughan J, Criner GJ. The effects of high-flow vs low-flow oxygen on exercise in advanced obstructive airways disease. Chest 2004;126:1108-15.

54. Jaber S, Monnin M, Girard M, Conseil M, Cisse M, Carr J, et al. Apnoeic oxygenation via high-flow nasal cannula oxygen combined with non-invasive ventilation preoxygenation for intubation in hypoxaemic patients in the intensive care unit: the single-centre, blinded, randomised controlled OPTINIV trial. Intensive Care Med 2016;42:1877-87.

55. Miguel-Montanes R, Hajage D, Messika J, Bertrand F, Gaudry S, Rafat C, et al. Use of high-flow nasal cannula oxygen therapy to prevent desaturation during tracheal intubation of intensive care patients with mild-to-moderate hypoxemia. Crit Care Med 2015;43:574-83.

56. Vourc'h M, Asfar P, Volteau C, Bachoumas K, Clavieras N, Egreteau PY, et al. High-flow nasal cannula oxygen during endotracheal intubation in hypoxemic patients: a randomized controlled clinical trial. Intensive Care Med 2015;41:1538-48.

57. Hernández G, Vaquero C, González P, Subira C, Frutos-Vivar F, Rialp G, et al. Effect of postextubation high-flow nasal cannula vs conventional oxygen therapy on reintubation in low-risk patients: a randomized clinical trial. JAMA 2016;315:1354-61.

58. Hernández G, Vaquero C, Colinas L, Cuena R, González P, Canabal A, et al. Effect of postextubation high-flow nasal cannula vs noninvasive ventilation on reintubation and postextubation respiratory failure in high-risk patients: a randomized clinical trial. JAMA 2016;316:1565-74.

59. Rochwerg B, Einav S, Chaudhuri D, Mancebo J, Mauri T, Helviz Y, et al. The role for high flow nasal cannula as a respiratory support strategy in adults: a clinical practice guideline. Intensive Care Med 2020;46:2226-37.

60. Esteban A, Frutos-Vivar F, Muriel A, Ferguson ND, Peñuelas $\mathrm{O}$, Abraira V, et al. Evolution of mortality over time in patients receiving mechanical ventilation. Am J Respir Crit Care Med 2013;188:220-30.

61. Sun Z, Sessler DI, Dalton JE, Devereaux PJ, Shahinyan A, Naylor AJ, et al. Postoperative hypoxemia is common and persistent: a prospective blinded observational study. Anesth Analg 2015;121:709-15.

62. Nafiu OO, Ramachandran SK, Ackwerh R, Tremper KK, Campbell DA Jr, Stanley JC. Factors associated with and consequences of unplanned post-operative intubation in elderly vascular and general surgery patients. Eur J Anaesthesiol 2011;28:220-4.

63. Ramachandran SK, Nafiu OO, Ghaferi A, Tremper KK, Shanks A, Kheterpal S. Independent predictors and outcomes of unantic- 
ipated early postoperative tracheal intubation after nonemergent, noncardiac surgery. Anesthesiology 2011;115:44-53.

64. Brueckmann B, Villa-Uribe JL, Bateman BT, Grosse-Sundrup M, Hess DR, Schlett CL, et al. Development and validation of a score for prediction of postoperative respiratory complications. Anesthesiology 2013;118:1276-85.

65. Nava S, Hill N. Non-invasive ventilation in acute respiratory failure. Lancet 2009;374:250-9.

66. Corley A, Bull T, Spooner AJ, Barnett AG, Fraser JF. Direct extubation onto high-flow nasal cannulae post-cardiac surgery versus standard treatment in patients with a $\mathrm{BMI} \geq 30$ : a randomised controlled trial. Intensive Care Med 2015;41:887-94.

67. Yu Y, Qian X, Liu C, Zhu C. Effect of high-flow nasal cannula versus conventional oxygen therapy for patients with thoracoscopic lobectomy after extubation. Can Respir J 2017; 2017:7894631.

68. Stéphan F, Barrucand B, Petit P, Rézaiguia-Delclaux S, Médard A, Delannoy B, et al. High-flow nasal oxygen vs noninvasive positive airway pressure in hypoxemic patients after cardiothoracic surgery: a randomized clinical trial. JAMA 2015;313:2331-9.

69. Huang HW, Sun XM, Shi ZH, Chen GQ, Chen L, Friedrich JO, et al. Effect of high-flow nasal cannula oxygen therapy versus conventional oxygen therapy and noninvasive ventilation on reintubation rate in adult patients after extubation: a systematic review and meta-analysis of randomized controlled trials. J Intensive Care Med 2018;33:609-23.

70. Lu Z, Chang W, Meng S, Xue M, Xie J, Xu J, et al. The effect of high-flow nasal oxygen therapy on postoperative pulmonary complications and hospital length of stay in postoperative patients: a systematic review and meta-analysis. J Intensive Care Med 2020;35:1129-40.

71. Azoulay E, Lemiale V, Mokart D, Pène F, Kouatchet A, Perez P, et al. Acute respiratory distress syndrome in patients with malignancies. Intensive Care Med 2014;40:1106-14.

72. Keenan SP, Sinuff T, Burns KE, Muscedere J, Kutsogiannis J, Mehta S, et al. Clinical practice guidelines for the use of noninvasive positive-pressure ventilation and noninvasive contin- uous positive airway pressure in the acute care setting. CMAJ 2011;183:E195-214.

73. Mokart D, Geay C, Chow-Chine L, Brun JP, Faucher M, Blache JL, et al. High-flow oxygen therapy in cancer patients with acute respiratory failure. Intensive Care Med 2015;41:2008-10.

74. Coudroy R, Jamet A, Petua P, Robert R, Frat JP, Thille AW. Highflow nasal cannula oxygen therapy versus noninvasive ventilation in immunocompromised patients with acute respiratory failure: an observational cohort study. Ann Intensive Care 2016;6:45.

75. Harada K, Kurosawa S, Hino Y, Yamamoto K, Sakaguchi M, Ikegawa S, et al. Clinical utility of high-flow nasal cannula oxygen therapy for acute respiratory failure in patients with hematological disease. Springerplus 2016;5:512.

76. Hui D, Morgado M, Chisholm G, Withers L, Nguyen Q, Finch C, et al. High-flow oxygen and bilevel positive airway pressure for persistent dyspnea in patients with advanced cancer: a phase II randomized trial. J Pain Symptom Manage 2013;46:463-73.

77. Epstein AS, Hartridge-Lambert SK, Ramaker JS, Voigt LP, Portlock CS. Humidified high-flow nasal oxygen utilization in patients with cancer at Memorial Sloan-Kettering Cancer Center. J Palliat Med 2011;14:835-9.

78. Demoule A, Vieillard Baron A, Darmon M, Beurton A, Géri G, Voiriot G, et al. High-flow nasal cannula in critically III patients with severe COVID-19. Am J Respir Crit Care Med 2020; 202:1039-42.

79. Franco C, Facciolongo N, Tonelli R, Dongilli R, Vianello A, Pisani L, et al. Feasibility and clinical impact of out-of-ICU noninvasive respiratory support in patients with COVID-19-related pneumonia. Eur Respir J 2020;56:2002130.

80. Grieco DL, Menga LS, Cesarano M, Rosà T, Spadaro S, Bitondo $\mathrm{MM}$, et al. Effect of helmet noninvasive ventilation vs high-flow nasal oxygen on days free of respiratory support in patients with COVID-19 and moderate to severe hypoxemic respiratory failure: the HENIVOT randomized clinical trial. JAMA 2021;325:1731-43. 